\title{
Use of Cone-Beam Computed Tomography in the Diagnosis and Treatment of an Unusual Canine Abnormality
}

*Archana Gopalakrishnan, ${ }^{1}$ Unnikrishna K., ${ }^{2}$ Anita Balan, ${ }^{3}$ Haris P. S. ${ }^{1}$

$$
\text { استخدام التصوير المقطعي بالموجات المخروطية في تشخيص وعلاج تشوهات المنياب غير المعتاد }
$$

أرتشانا غويالاكريشنان، أونكريشنا ك.، أنيتا بالان، هـاريس ب. س.

ABSTRACT: Diagnosis and treatment planning are important for successful endodontic treatment. We report a 24-year old male who presented to the Government Dental College in Kozhikode, Kerala, India, in 2015 with pain in his right upper canine. A digital periapical radiograph indicated the presence of a supernumerary tooth superimposing the root of the canine. However, cone-beam computed tomography (CBCT) confirmed that the supernumerary tooth was an illusion and that the canine root had a sharp invagination involving the labial and pulpal dentin surfaces, with evidence of periapical bone destruction. A blunt resection was performed at the level of the invagination and the resected end was filled with a dentin substitute. At a one-year follow-up, the patient was asymptomatic and the periapical region appeared to be healing well. This report highlights the importance of $\mathrm{CBCT}$ in visualising abnormal canine morphology, thus allowing appropriate endodontic treatment.

Keywords: Diagnostic Imaging; Cone-Beam Computed Tomography; Tooth Abnormalities; Case Report; India.

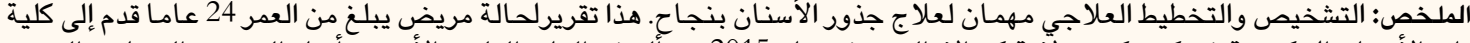

$$
\begin{aligned}
& \text { طب الأسنان الحكومية في كوزيكود، ولآية كيرالا، الهند، في جال فام }
\end{aligned}
$$

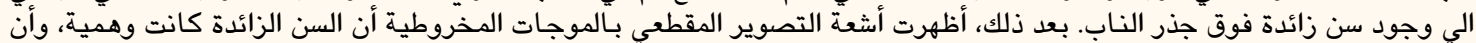

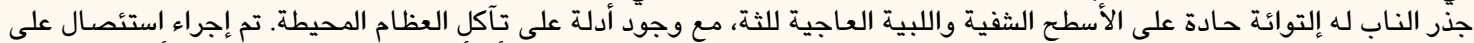

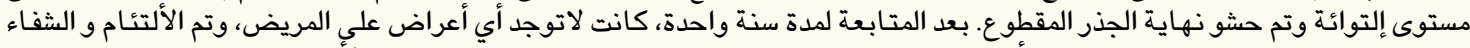

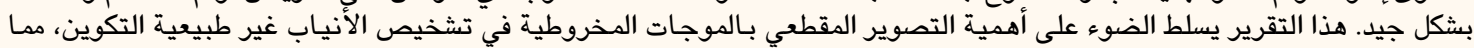

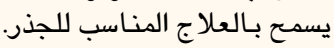

$$
\begin{aligned}
& \text { الكلمات المفتاحية؛ التشخيص التصويري؛ التصوير المقطعي بالموجات المخروطية؛ تشوهـات الأسنان؛ تقرير حالة؛ الهند. }
\end{aligned}
$$

$\mathrm{W}$ Hile Dental Radiology plays a Vital role in visualising dental pathologies, it is important that endodontists opt for the right imaging modality to ensure a correct diagnosis and, subsequently, successful treatment. Currently, the use of cone-beam computed tomography (CBCT) allows visualisation of related anatomic structures in three dimensions, thus improving overall diagnostic efficacy and accuracy in many clinical situations. ${ }^{1,2}$ In addition, with the ability to obtain a small field of view in CBCT imaging, high-resolution images can be obtained while minimising patient exposure to ionising radiation and reducing reconstruction time. ${ }^{3}$ Among endodontists, CBCT has become a popular imaging modality as it allows greater insight into root canal morphology and can aid in the early detection of apical pathosis. ${ }^{4}$

\section{Case Report}

A 24-year old male presented to the Oral Medicine Department of the Government Dental College in Kozhikode, Kerala, India, in 2015 with a complaint of pain in his right upper canine of four days' duration. His medical and family history was normal. He had previously undergone an unsuccessful root canal treatment, after which he had been referred to an endodontic specialist. Clinically, the crown of the canine appeared to have a normal morphology with evidence of an access opening in the palatal aspect. On palpation, the attached gingiva of the canine revealed a depression $5 \mathrm{~mm}$ apical to the gingival margin, very close to a bony prominence. The patient reported that the tooth was tender upon percussion. 

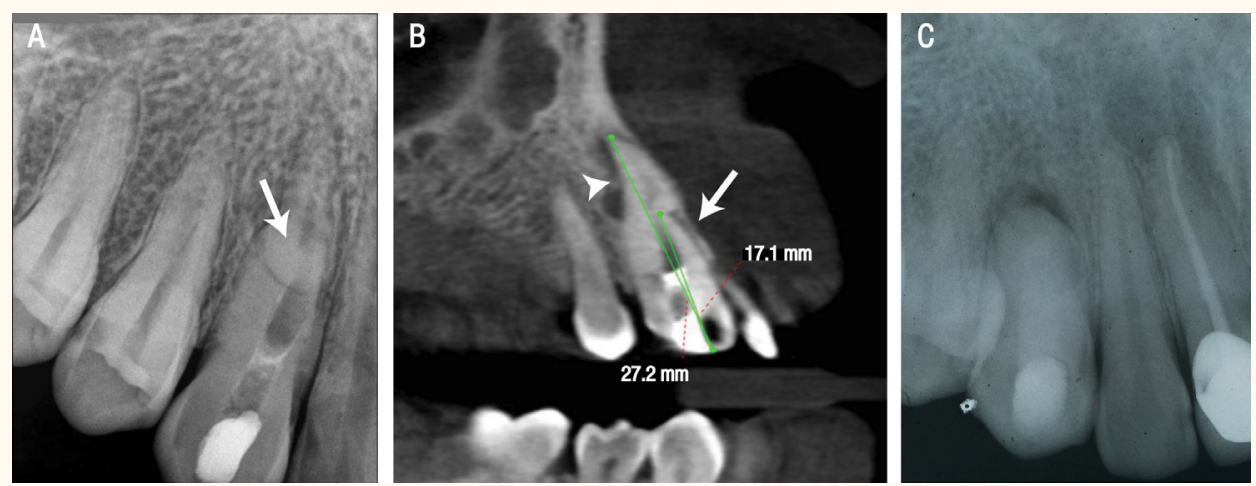

Figure 1: A: Digital periapical radiograph of a 24-year old male with right upper canine pain showing a supernumerary tooth superimposing the apical third of the canine (arrow). B: Cone-beam computed tomography of the canine in the sagittal aspect revealing altered root morphology with a sharp indentation in the labial aspect (arrow) and an ill-defined radiolucency (arrowhead) in the palatal and apical aspect of the apical third of the root. C: Radiograph of the periapical region one year following treatment showing satisfactory healing.

A digital periapical radiograph of the tooth showed a canine with a short blunt root and attempted root canal preparation with inadequate access to the cavity. The apical third of the root appeared to be superimposed by the crown of an impacted supernumerary tooth [Figure 1A]. Additional exposure with 10-15 degree changes in horizontal angulation revealed only minimal changes in the position of the supernumerary tooth. In accordance with as low as reasonably achievable' principles, $\mathrm{CBCT}$ of the maxilla was performed at a dose of $19 \mu \mathrm{Sv}$ (CS 9300 System, Carestream Health Inc., Rochester, New York, USA). The axial, sagittal and transverse CBCT reformations were inspected using $0.16 \mathrm{~mm}$ slice thicknesses. Interestingly, this revealed that there was no supernumerary tooth; instead, the radicular portion of the canine was malformed, with a sharp invagination on the labial aspect of the middle-third of the root involving the labial and pulpal dentin surfaces, giving the appearance of a dens in dente. The entire tooth measured $27.2 \mathrm{~mm}$ from the cusp tip to the end of the root, with the invagination $17.1 \mathrm{~mm}$ from the cusp tip. In addition, there was an ill-defined radiolucency in the apical and palatal aspect of the apical third of the root, suggestive of periapical bone destruction [Figure 1B].

Subsequently, an access opening to the tooth was secured via the palatal aspect and the canal was negotiated up to the root tip. Biomechanical preparation was performed until the measured length of the invagination and a dentin substitute (Biodentine $e^{\circledR}$, Septodont, Paris, France) was inserted. Two weeks later, a labial full-thickness rectangular mucoperiosteal flap was elevated following the administration of local anaesthesia using 2\% lidocaine and 1:100,000 adrenaline. There was evidence of dehiscence in the apical third of the root. The labial cortical plate coronal to the dehiscence was explored, exposing the sharp indentation on the middle third of the root. A blunt resection at 45 degrees was performed at the level of the invagination, with the resected end then filled with the dentin substitute (Biodentine ${ }^{\circledR}$, Septodont). The surgical bed was rinsed with saline and the flap was secured with sutures.

Postoperatively, the retrograde filling was assessed using radiography. The resected end was subjected to ground sectioning and light microscopy revealed normal-looking dentin and cementum. At a one-year follow-up, the patient was asymptomatic and a periapical radiograph showed healing of the periapical region [Figure 1C].

\section{Discussion}

Radiographically, the accuracy of detection of the number and morphology of root canals greatly depends on the angulation of the incident X-ray beam and the superimposition of any adjacent structures. ${ }^{5}$ Conventional radiography merely displays a twodimensional (2D) image of a three-dimensional (3D) structure; as such, intra-oral periapical radiographs only highlight features in the mesiodistal plane and it is often difficult to visualise the buccolingual dimension of the tooth. ${ }^{6}$ However, with the advent of volumetric computerised tomography or $\mathrm{CBCT}$, visualisation of a tooth in all dimensions is possible. These newer imaging modalities provide faster results and greater image resolution, making diagnosis and treatment planning easier. ${ }^{1-3}$

The current case described a patient who presented with pain in the right upper canine. On periapical radiography, the root of the canine appeared extremely short and blunt, with the apical third seemingly superimposed by the crown of an impacted 


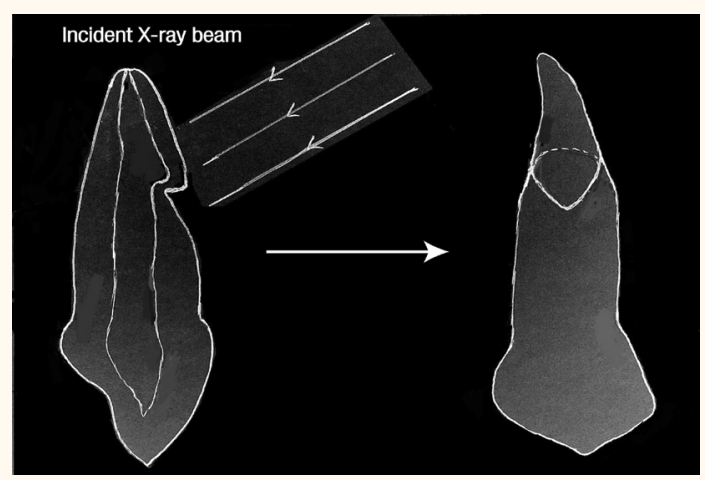

Figure 2: Diagram showing how the angulation of an incident X-ray beam in two-dimensional imaging of a canine with unusual morphology can create the illusion of a supernumerary tooth.

supernumerary tooth. However, there was no evidence of any supernumerary teeth upon CBCT. Rather, this newer diagnostic imaging technique revealed a long canine with altered root morphology and an invagination at the middle-third of the root. This was particularly noticeable in the midsagittal aspect wherein the root canal took a slightly tortuous course at the middle-third to reach the apex. The illusion of the supernumerary tooth on the periapical radiograph was formed by the overlapping of two segments of the root of the canine along the direction of the X-ray beam [Figure 2]. This case highlights the difficulty of assessing the spatial relationships of a tooth root via $2 \mathrm{D}$ imaging alone.

Reconstructed CBCT scans are invaluable for assessing teeth with unusual anatomies, such as those with an unusual number of roots, dilacerated teeth and dens in dente. ${ }^{7}$ Wang et al. similarly reported that CBCT has a significantly higher sensitivity compared to periapical radiographs when detecting cracks in teeth in all planes. ${ }^{8}$ Nakata et al. emphasised that relevant $\mathrm{CBCT}$ views and slices are necessary for accurate planning in periapical microsurgery. ${ }^{9}$ In the present case, $\mathrm{CBCT}$ allowed the accurate diagnosis and precise assessment of an unusual root morphology and periapical pathosis not visible on conventional diagnostic radiography, thus paving the way for an appropriate treatment plan.

\section{Conclusion}

Conventional intra-oral radiography reveals an image of a tooth in two dimensions, with limited information regarding its spatial relationships with other anatomical structures in the third dimension. This may potentially result in inaccurate diagnoses and unnecessary or inappropriate treatments. For endodontic patients, treatment planning should be based on a comprehensive evaluation using all diagnostic modalities available, including newer 3D imaging techniques, particularly in cases where conventional imaging is inconclusive.

\section{References}

1. Nair MK, Nair UP. Digital and advanced imaging in endodontics: A review. J Endod 2007; 33:1-6. doi: 10.1016/j. joen.2006.08.013.

2. Patel S, Durack C, Abella F, Shemesh H, Roig M, Lemberg K. Cone beam computed tomography in endodontics: A review. Int Endod J 2015; 48:3-15. doi: 10.1111/iej.12270.

3. Scarfe WC, Levin MD, Gane D, Farman AG. Use of cone beam computed tomography in endodontics. Int J Dent 2009; 2009:634567. doi: 10.1155/2009/634567.

4. Leonardi Dutra K, Haas L, Porporatti AL, Flores-Mir C, Nascimento Santos J, Mezzomo LA, et al. Diagnostic accuracy of cone-beam computed tomography and conventional radiography on apical periodontitis: A systematic review and meta-analysis. J Endod 2016; 42:356-64. doi: 10.1016/j. joen.2015.12.015.

5. Patel S, Dawood A, Whaites E, Pitt Ford T. New dimensions in endodontic imaging: Part 1 - Conventional and alternative radiographic systems. Int Endod J 2009; 42:447-62. doi: 10.1111 /j.1365-2591.2008.01530.x.

6. Cohenca N, Simon JH, Roges R, Morag Y, Malfaz JM. Clinical indications for digital imaging in dento-alveolar trauma: Part 1 - Traumatic injuries. Dent Traumatol 2007; 23:95-104. doi: 10.1111/j.1600-9657.2006.00509.x.

7. Wang S, Xu Y, Shen Z, Wang L, Qiao F, Zhang X, et al. The extent of the crack on artificial simulation models with CBCT and periapical radiography. PloS One 2017; 12:e0169150. doi: 10.1371/journal.pone.0169150.

8. Patel S. New dimensions in endodontic imaging: Part 2 - Cone beam computed tomography. Int Endod J 2009; 42:463-75. doi: 10.1111/j.1365-2591.2008.01531.x

9. Nakata K, Naitoh M, Izumi M, Inamoto K, Ariji E, Nakamura H. Effectiveness of dental computed tomography in diagnostic imaging of periradicular lesion of each root of a multirooted tooth: A case report. J Endod 2006; 32:583-7. doi: 10.1016/j. joen.2005.09.004 